\title{
Households' perceptions of private sector municipal solid waste management services: A binary choice analysis
}

\author{
${ }^{1}$ *E. E. Ezebilo; ${ }^{2}$ E. D. Animasaun \\ ${ }^{1}$ Swedish University of Agricultural Sciences, Southern Swedish Forest Research Center, \\ Alnarp, Sweden \\ ${ }^{2}$ Malmö University, Department of Public Health Malmö, Malmö, Sweden
}

Received 23 December 2010; revised 28 April 2011; accepted 8 August 2010

\begin{abstract}
The increase in the volume of waste materials discharged to the environment and deterioration of environmental quality in urban areas have been an issue of major concern for many governments in developing countries. To improve effectiveness and efficiency in the delivery of waste management services some of the governments have involved the private sector. This study uses binary choice model to examine urban residents' perceptions regarding solid waste management that involves the private sector and what could be done to improve the waste management services. The data were generated from survey conducted in 238 households in Ilorin in southwest Nigeria. The results show that most of the respondents were not satisfied with solid waste management in the Ilorin. Binary logit model estimates reveal that the respondents' perceptions regarding waste management were determined by income, travel time to dump site and marital status, as well as awareness of laws regarding waste disposal and activities of sanitary inspectors. For solid waste management in urban areas to be sustainable, it requires participation of the government, private sector and residents. The results generated from this study can help waste management authorities in designing a more sustainable waste management strategy in Ilorin, as well as in other cities that have similar conditions.
\end{abstract}

Keywords: Binary logit model; Environmental quality; Private participation; Sustainability

\section{INTRODUCTION}

Waste is organic and inorganic material produced by households, commercial and industrial establishments that have no economic value to the owner (UNICEF, 2006). Waste management includes collection, transportation, processing, recycling or disposal of waste materials. Increase in population, improvement in wages and expansion of urban areas contribute to the increase in the amount of waste generated in less developed countries (UNICEF, 2001; Blanchard, 2009), i.e. increase in population and income brings about an increase in demand and production of goods and services (Tehrani et al., 2009; 2010; Varian, 2010), thereby waste materials are discharged into the environment. The increasing amount of waste arising from urban areas and its consequent disposal has been one of the major environmental and economic problems in most developing countries (Brunner and Fellner, 2007; Blight, 2008). In some developing countries urban

*Corresponding Author Email: eugene.ezebilo@slu.se Tel.: +4640415197; Fax: +4640462325 residents often dispose their waste materials into the nearest lowlands, rivers and sea (Nouri et al., 2009; Kanat, 2010). This inappropriate waste disposal method threatens the environment, i.e. deterioration of environmental quality, e.g. air and water pollution (Chien and Shih, 2007; Asase, 2009). This increases the costs of waste management, i.e. clean up costs and costs associated with public health (Asafu-Adejaye, 2000; Cointreau, 2006; De Oliveria and Borenstein, 2007). Effective waste management leads to improvement in environmental quality, i.e. an environmental good. Provision of environmental goods requires government intervention because the goods have the characteristics of non-excludability and nonrivalry (Harris, 2006; Hanley, et al., 2007). That is, once the good is produced it is practically impossible to prevent anyone from consuming it and the same unit of the good can be consumed by more than one person. Because it is impossible to exclude people from using environmental goods, a free-rider problem arises 
(Tietenberg and Lewis, 2010), i.e. individuals refuse to pay or underestimate the maximum amount they would be willing to pay for the good. The reason is they know that they can consume the good even if they do not pay (fully) for it. Hence, there is not sufficient incentive for the private sector to provide the good.

Ilorin, the capital of Kwara State in southwest Nigeria has experienced rapid urbanization and population growth (Adedibu, 1985; National Population Commission, 2006), which in turn have the effect of increasing the amount of waste generated in the Ilorin. In the past, the government had taken on the primary responsibility for the management of waste but it has not been very effective. To improve effectiveness in waste management, the Kwara State Government enacted an environmental sanitation edict in 1984. The edict made it imperative for Ilorin residents to clean their environment on every second Saturday of the month. These efforts were geared towards keeping the Ilorin clean of waste materials, however this has not been very successful. In order to increase efficiency in waste management in Ilorin the Kwara State Government encouraged private sector participation. For example, O'la Klean a private firm was contracted in 2004 and was charged with the responsibility of keeping Ilorin clean, and formalise recycling process in the state. Presently, O'la Klean is involved in waste management in partnership with the Kwara State Waste Management Council (a governmental agency). The challenge of effective and efficient instruments to manage household waste materials has become a priority for policy-makers in Kwara State. To tackle the challenge the knowledge of people's attitudes and preferences regarding waste management is important in developing sustainable waste management strategies. Urban residents' preferences regarding waste management will help in planning the strategies. This is important because the success of waste management policy in urban areas is to a large degree dependent on acceptance by the residents. Although waste may occur in solid, liquid and gaseous states, this study has focused on solid waste because it is the most conspicuous one and can be easily noticed by the urban residents. The aim of this study is to examine, using binary choice model, Ilorin residents' perceptions of solid waste management services involving private sector, as well as the determinants of their perceptions and to explore possible strategies to improve the services. The pre- test survey for the study was carried out in April 2009 and the major survey was during the months of June and July in Ilorin in southwest Nigeria.

\section{MATERIALS AND METHODS}

Description of the study area

Ilorin, latitude $8^{\circ} 30^{\prime} \mathrm{N}$ and longitude $4^{\circ} 33^{\prime} \mathrm{E}$, the capital of Kwara State in southwest Nigeria is one of the largest cities in the country (Fig. 1). It has an area of $100 \mathrm{~km}^{2}$ (Kwara State Nigeria, 1997). Ilorin has a humid climate characterized by dry and wet seasons and the annual mean total rainfall of about $1150 \mathrm{~mm}$ (Jimoh, 1997). The wet season is between March and October while the dry season is between the months of November and February. The mean monthly temperature of Ilorin ranges from $25^{\circ} \mathrm{C}$ to $29^{\circ} \mathrm{C}$. Ilorin falls within the derived savannah vegetation zone characterized by the existence of tall grasses (e.g. guinea grass) and sparsely distributed tall trees such as baobab, locust beans, shearbutter, Acacia. Like many traditional cities in Nigeria, Ilorin retains the characteristics of traditional town alongside a modern urban center. Various types of human activities thrive in the study area. The activities include farming, transportation and a host of other professions. In Ilorin, in 1952 the population was 41,000 , however it was estimated to be 320,000 in 1973 (Olorunfemi, 1982), 477,500 in 1980 (Adedibu, 1985) and 572,178 in 1991. In 2006 , the population of Ilorin was 766,000 (National Population Commission, 2006). Ilorin has about 21 dump sites placed by Kwara State Environmental Protection Agency and about 108 bins spatially distributed by O'la Klean / Kwara State Waste Management Council within Ilorin metropolis (Kwara State Management Council, 2007). There are some illegal dump sites scattered all over the city, mainly at road junctions and interstitial spaces within neighbourhoods. These dump sites often appear and disappear after the national environmental sanitation days (second and last Saturdays of every month). Ilorin has been selected for this study because of the increasing population, urbanization and the increase in waste disposal problems, which make it a suitable site for the study of this nature.

\section{Survey design and data collection}

The data collection was made by means of handdelivered questionnaires and interviews that were designed and tested in a town outside the study area. 


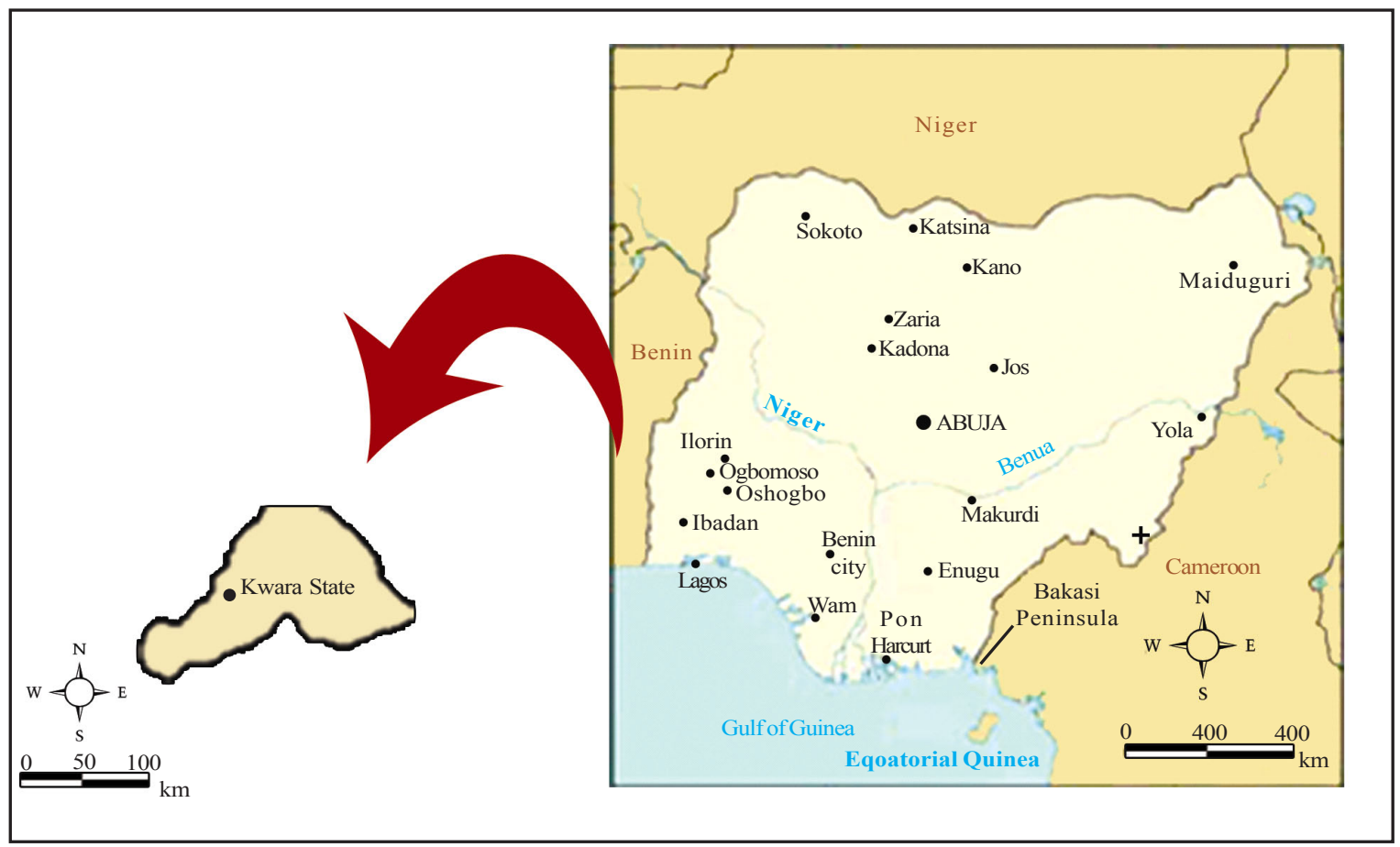

Fig. 1: Map of Nigeria showing the location of Ilorin in southwest of the country

People who had no formal education were interviewed based on the questions in the questionnaire, while people who had formal education were handed a copy of the questionnaire. The questionnaire was developed during focus group discussions and pre-test surveys which were conducted in April 2009 in thirty randomly selected households. After the pre-test surveys, wordings of some questions were adjusted to capture concerns raised by survey assistants and respondents. The major survey was conducted during the months of June and July 2009. Six survey assistants were recruited and trained for three days. The assistants were fluent in the local language (Yoruba) of the study area and were familiar with Ilorin. The Ilorin was divided into three subdivisions namely: the old residential area, the new residential area and the government reservation area. Three hundred and thirty two households were randomly selected $(111,111$, and 110 in the sub-divisions). If a resident declined the questionnaire or to be interviewed, or there was no one home at a residence contacted, the survey assistants proceeded to the next residence until the desired sample size of respondents was achieved. The questionnaires and interviews were administered at both weekdays and weekends as well as during working hours and after working hours, in order to include as many categories of the population as possible during the survey period. Amongst the three hundred and thirty two questionnaires handed out to Ilorin residents, only $232(70 \%)$ responded to the questionnaire after two reminders. All people (18) who had no formal education agreed to be interviewed. In total, 250 (71\%) responded to the survey and 238 of the responses were useable for statistical analysis. Thus, about $5 \%$ of the responses were not included in the analysis but this should not have a significant effect on the results of the study. The responses that were not useable contained many unanswered questions. The questionnaire included forced choice, scaled and open-ended questions. Qualitative questions were included so respondents could expand on their ideas and opinions. Quantitative questions gave measurable insights into respondents' waste behaviour and future concerns. This paper is based on seven questions in the main questionnaire. The questions comprised of the respondents' gender, income and marital status. Respondents were asked whether they were aware about laws regarding waste disposal and whether sanitary inspectors do visit 
their area frequently. They were asked about the travel time from their residence to the nearest dumpsite and whether they were more satisfied with the present solid waste management services in Ilorin than when only government (i.e. before 2004) was involved in the services. Before responding to the question regarding whether the respondents were more satisfied with the present solid waste management services, they were reminded to pay more emphasis on the frequency of collection of solid waste, distance from their home to the nearest dump site and the environmental quality in Ilorin.

\section{The econometric model}

Before 2004, government has been the only agency in charge of waste management in Ilorin. In order to increase effectiveness and efficiency the government encouraged private participation in waste management. It is assumed that the involvement of private sector will help to increase the frequency of collection, transportation and disposal of waste (e.g. solid waste) thus helping to keep Ilorin cleaner. To examine whether private sector participation in solid waste management in Ilorin has lived up to expectation, one way of doing this is to assess residents' perceptions regarding solid waste management. In this study a sample of Ilorin residents were asked whether they were satisfied with solid waste management in the Ilorin as opposed to (e.g. before 2004) when only the government was mainly in charge of waste management. The authors of this study assume that if the respondent $i$ is satisfied with the present solid waste management services, then private sector participation has contributed to increase effectiveness and efficiency (i.e. the respondent derives more utility from services involving the private sector than the one that is dominated by the government $\left(U_{i 1}>U_{i 0}\right)$. The respondent's opinion regarding waste management is composed of two parts: a systematic term, which depends on an attributes vector $X$ (income, distance of respondent's residence to dumpsite, gender, etc.) and another random one, $\varepsilon_{\mathrm{i}}$ (Ezebilo et al., 2010):

Waste_ $P_{i}=X_{i} \beta+\varepsilon_{i}$

Where Waste_ $\mathrm{P}_{i}$ is the respondent's perception of solid waste management (satisfied, not satisfied), $X_{i}$ is the personal characteristics of the respondent $i, \hat{a}$ represents parameters to be estimated and $\varepsilon_{\mathrm{i}}$ is the disturbance term. Since Waste_ $\mathrm{P}_{\mathrm{i}}$ is latent, i.e. not observable. Therefore, let $l_{i}$ be the indicator variable, so that:

$$
\begin{aligned}
I_{i}=1, \text { if Waste_ } \mathrm{P}_{\mathrm{i}} & =\text { satisfied } \\
& =0, \text { not satisfied }
\end{aligned}
$$

In this study, the authors can distinguish between two arrangements namely, satisfied or not satisfied of solid waste management. Given the binomial nature of such arrangements, and assuming that the respondent can identify the preferred arrangement, a binomial logit econometric technique (Greene, 2003; Ezebilo, 2010a) can be used in the empirical investigation of factors associated with the perception of the respondent. The probability that the respondent $i$ will choose the 'satisfied' option can be expressed as binomial logit model:

$\operatorname{Prob}[$ satisfied $]=\frac{e^{X_{i \beta}}}{1+e^{X_{i \beta}}}$

Eq. 3 can be expressed as:

$\log \left[\frac{\operatorname{Prob}(\text { satisfied })}{1-\operatorname{Prob}(\text { satisfied })}\right]=\beta_{0}+\beta_{1} X_{1}+\ldots+\beta_{n} X_{n}+\varepsilon_{i}$

Where, Prob(satisfied) is the probability that the respondent is satisfied with solid waste management, $\hat{a}_{0}$ is the intercept, $\hat{a}_{1}$ is the coefficient associated with the respondents' household income $\mathrm{X}_{1}$ and $\hat{a}_{n}$ a vector of regression coefficients associated with other personal characteristics of the respondent $\mathrm{X}_{\mathrm{n}}$ and $\varepsilon_{\mathrm{i}}$ is the error term which is logistically distributed.

Marginal effect is a measure of the instantaneous effect on the predicted probability of response variable when the other covariates are kept fixed (Greene, 2003; Verbeek, 2007). For continuous independent variables marginal effects are obtained by computing the derivative of the conditional mean function with respect to the independent variable (Ezebilo, 2010b). For dummy variable marginal effects are calculated as the difference in the estimated probabilities with the dummy variable equal to one and zero (Madden et al., 2005). The marginal effect for continuous independent variable is:

$\frac{\partial E[y X]}{\partial X}=\frac{d F\left(\beta^{\prime} X\right)}{d\left(\beta^{\prime} X\right)}=f\left(\beta^{\prime} X\right) \beta$

Where, $\mathrm{y}$ is a choice variable, $\mathrm{X}$ is a vector of explanatory variables, $\hat{a}$ is a vector of parameter estimates, $F$ is the cumulative distribution function 
and $f$ is the corresponding probability density function. For dummy independent variable, $z$ the marginal effect is:

$$
\begin{aligned}
\Delta F z & =\operatorname{Pr} o b[y=1 \mid z=1]-\operatorname{Pr} o b[y=1 \mid z=0] \\
& =F\left(\beta^{\prime} X+\alpha z \mid z=1\right)-F\left(\beta^{\prime} X+\alpha z \mid z=0\right)
\end{aligned}
$$

The binary logit model was estimated using the LIMDEP NLOGIT version 4.0.1 statistical package (Table 3). The effect of respondents' characteristics on perception of solid waste management Waste $\mathrm{P}_{\mathrm{i}}$ was examined using the logit model (Table 3). Explanation of variables that were used in the analysis is presented in Table 1.

Econometric analysis with cross-sectional data is usually associated with problems of multi-collinearity (Hassan and Nhemachena, 2008). Multi-collinearity often leads to biased parameter estimates (O'Brien, 2007). The Variance inflation factor (VIF) is a widely used measure to examine the degree of multicollinearity of the ith independent variable with other independent variables in a regression model (Gujarati, 2006). VIF indicates how much the estimated variance of the ith regression coefficient is increased above what it would be if coefficient of determination $\left(\mathrm{R}^{2}\right)$ equalled zero, which is a situation where the ith independent variable is orthogonal to the other independent variables in the analysis. VIF provides an indication of the effects of multi-collinearity on the variance of the ith regression coefficient. A maximum VIF value greater 10 is often taken as an indication that multi-collinearity may be unduly influencing the least square estimate (Neter et al., 1989). Ordinary least squares regression model was fitted and the model was tested for multi-collinearity using VIF (Table 1). The VIF of all included variables were much less than 10 (Table1), which indicates that multi-collinearity is not a serious problem in the estimated model.

\section{RESULTS AND DISCUSSION}

About $18 \%$ of the respondents were satisfied with the solid waste management during the period of this study, while $82 \%$ were not satisfied (Table 1 ). This shows that most of the respondents were not satisfied with private participation in solid waste management. Similar results have been reported in other studies by Dangi et al. (2009) who found that people are generally dissatisfied with solid waste management in Kathmandu Metropolitan City; Longe et al. (2009) reported that most Ojo residents in Lagos, Nigeria expressed their concerns about the poor solid waste management situation in their area. It suggests that private participation has not been able to increase efficiency and effectiveness in solid waste management. This is in agreement with the findings of Oteng-Ababio (2010) who found the presence of structural failures in the governance of public-private partnership in solid waste management in Accra.

\begin{tabular}{|c|c|c|c|c|}
\hline Variable & Description & Mean & $\%$ & VIF \\
\hline \multirow[t]{3}{*}{ Waste_P } & $\begin{array}{l}\text { Respondent's perception of solid waste management (satisfied=1, } 0 \\
\text { otherwise) }\end{array}$ & & & \\
\hline & Satisfied & NA & 17.8 & NA \\
\hline & Not satisfied & NA & 82.2 & NA \\
\hline Income & Household income per year (NGN) & 441,322 & NA & 1.020 \\
\hline Time & Travel time from respondent's home to dump site ( $\mathrm{min}$ ) & 7.753 & NA & 1.115 \\
\hline \multirow[t]{3}{*}{ Gender } & Respondent's gender (male $=1,0=$ female $)$ & & & 1.048 \\
\hline & Male & NA & 56.6 & NA \\
\hline & Female & NA & 43.4 & NA \\
\hline \multirow[t]{3}{*}{ Marital } & Respondent's marital status & & & 1.025 \\
\hline & Married $=1$ & NA & 57.44 & NA \\
\hline & Single $=0$ & NA & 42.56 & NA \\
\hline \multirow[t]{2}{*}{ Law } & $\begin{array}{l}\text { Respondent is aware of law regarding } \\
\text { indiscriminate waste disposal }\end{array}$ & & & 1.115 \\
\hline & $\begin{array}{l}\text { yes }=1 \\
0=\text { no }\end{array}$ & $\begin{array}{l}\text { NA } \\
\text { NA }\end{array}$ & $\begin{array}{l}61.98 \\
38.02\end{array}$ & $\begin{array}{l}\text { NA } \\
\text { NA }\end{array}$ \\
\hline \multirow[t]{3}{*}{ Inspect } & Sanitary inspectors activities are often noticed: & & & 1.025 \\
\hline & yes $=1$ no $=0$ & NA & 16.18 & \\
\hline & & NA & 83.82 & \\
\hline
\end{tabular}

Table 1: Descriptive statistics of respondents' characteristics

Nigerian Naira $(\mathrm{NGN}) 1=\mathrm{US} \$ 0.00649 ; \mathrm{NA}=$ Not applicable 
Although involvement of private sector in waste management can help to increase efficiency and effectiveness, it requires an organized public institution to monitor their activities. Sustainable solid waste management will require the involvement of all stakeholders concerned with generation of waste materials, collection and disposal as well as monitoring of activities regarding waste management (e.g. government, private sector and local residents). $85 \%$ of the female respondents were not satisfied with solid waste management while it was $80 \%$ for the male (Table 2). In many developing countries women are often involved in the disposal of household waste materials. If solid waste management system is ineffective, they are often the first to be hit by the waste disposal problems. This could be one of the reasons women participates more in recycling products than men as reported by Muderrisoglu and Altanlar (2011). This suggests that women are more likely to identify abnormalities in solid waste management and the need to involve them in monitoring the activities of private firms engaged in solid waste management. Most of the respondents who were married ( $86 \%$ Table 2$)$ were not satisfied with solid waste management. Married people often have larger household size as opposed to people who are single. Hence, married people tend to generate more waste materials and may be more affected when there are lapses in solid waste management system. More of the respondents who were familiar with waste disposal laws were satisfied as opposed to those who were not aware (Table 2). It appears that if people are informed about laws regarding waste management they would be in a better position to know how the system works and who to contact (e.g. waste management authorities) when the system is not functioning properly. The respondents who reside in areas where activities of sanitary inspectors were often noticed, were more satisfied (about $39 \%$ - Table 2). This indicates that if activities of private sector in solid waste management are monitored by public sector (for insctance, environmental protection agency), it will improve the effectiveness of the private sector.

The binary logit model estimates of the respondents' perceptions regarding solid waste management are reported in Table 3. The dependent variable was respondents' perceptions of solid waste management (satisfied, not satisfied). The likelihood ratio test statistic was statistically significant. This shows that the explanatory variables were collectively significant
Table 2: Respondents' perceptions of waste management

\begin{tabular}{lccc}
\hline Variable & $\begin{array}{c}\text { Satisfied } \\
(\%)\end{array}$ & $\begin{array}{c}\text { Not satisfied } \\
(\%)\end{array}$ & Total (\%) \\
\hline Gender & & & \\
Male & 19.56 & 80.04 & 100 \\
Female & 15.38 & 84.62 & 100 \\
Marital & & & \\
Married & 13.77 & 86.23 & 100 \\
Single & 23.07 & 76.92 & 100 \\
Law & & & \\
Yes & 20.67 & 79.33 & 100 \\
No & 13.04 & 86.96 & 100 \\
Inspect & & & \\
Yes & 38.46 & 61.54 & 100 \\
No & 13.79 & 86.21 & 100 \\
\hline
\end{tabular}

in the binary logit model. The probability that the respondent is satisfied was assumed to be a function of the respondent's characteristics. Positive coefficients imply that the probability of being satisfied increases as the corresponding variables increase. It was observed that there were some statistically significant variables that provide predictive information on the respondents' perceptions regarding solid waste management. Overall, the coefficients associated with income, travel time and marital status, as well as awareness of waste disposal laws and sanitary inspectors, provided the most predictive power regarding respondents' perceptions of solid waste management.

The coefficient associated with income has a negative and statistically significant impact on respondents' perceptions of solid waste management. This implies that respondents who have more money were less likely to be satisfied with solid waste management. However, increase in income by one unit (one Nigerian Naira) has no effect on the respondents' perceptions of solid waste management. A possible reason maybe that people who have more money have more capacity to purchase more consumer goods in quick to dispose packages (as canned foods and bottle drinks), thus, have higher tendency to generates more solid waste materials than people who have less money. The frequency of collection of waste material in the area of study do not often commensurate with the quantity of waste generated by residents (as it is often the case in many cities in developing countries). In this case people who have more money are more likely to be affected by the ineffectiveness in solid waste management than people who have less money. Hence, 
Int. J. Environ. Sci. Tech., 8 (4), 677-686, Autumn 2011

Table 3: Binary logit results for factors influencing perceptions of waste management

\begin{tabular}{lrrr}
\hline Variable & Coeff. & Std. error & Marginal effects \\
\hline Constant & -0.213 & 0.806 & -0.025 \\
Income & $-0.000002^{*}$ & 0.000001 & 0.000 \\
Time & $-0.188 * * *$ & 0.062 & -0.022 \\
Gender & 0.405 & 0.396 & 0.047 \\
Marital & $-0.727^{* *}$ & 0.379 & -0.089 \\
Law & $0.902^{* *}$ & 0.445 & 0.099 \\
Inspect & $1.550^{* * * *}$ & 0.456 & 0.257 \\
& & & - \\
Log likelihood function & -93.715 & - & - \\
Restricted log likelihood & -112.434 & - & - \\
Chi squared & 37.438 & - & - \\
Prob[chi squared $>$ value] & & - & - \\
McFadden Pseudo ${ }^{2}$ & $0.00000^{* * * *}$ & - & - \\
$\%$ correctly predicted & & & \\
\hline
\end{tabular}

$*, * *, * * *, * * * *$ represent $0.10,0.05,0.01$ and $<0.001$ levels of statistical significance, respectively.

the respondents who have more money were not satisfied with the solid waste management services.

The coefficient associated with travel time to dump site has a negative and statistically significant effect on the respondents' perceptions of solid waste management, i.e. the more the travel time to dump site the less likely would the respondents be satisfied with solid waste management. Increase in travel time by one unit (min) was associated with 0.022 decrease in probability of being satisfied with solid waste management. People who live farther from dump sites will have to travel for a longer period to dispose their waste materials, thus, they will be less likely to be satisfied with such waste management arrangement. Individuals have the tendency to minimize costs, dump sites located longer distance from home will attract more costs (like time and transportation cost). Moreover, the time they would have spent on other valuable activities are often spent on disposal of solid waste. As a remedy, the dump sites should be distributed in a way that people do not have to travel for a longer time to get access to it and the number of people making use of each dump site should be considered so as to give an idea of how frequent the dump site should be visited to evacuate the waste materials.

The coefficient associated with marital status has a negative and statistically significant effect on the respondents' perceptions of solid waste management, i.e. respondents who were married were less likely to be satisfied with solid waste management. If a respondent is married the probability of being satisfied with solid waste management decreases by 0.089 . People who are married have the tendency to generate more waste materials than those who are single, especially in many developing countries where there is high birth rate. When people are married it increases the number of people living in an area, increases the amount of waste materials generated by the people and consequently more waste materials are discharged into the environment. If the available waste management facilities do not have the capacity to handle more waste materials generated as a result of married people, it tends to lower the environmental quality of the area. Hence, married people will not be likely satisfied with the solid waste management system. Like many cities in developing countries, the area of study management plan regarding waste management is rigid and does not often take into account the increasing population. This often contributes to the illegal dumping of waste materials in Ilorin because the available facilities for solid waste management are often inadequate to cater for the amount of waste materials generated by the people. In the developed countries people are obliged to register their residential address. It helps in gathering the information regarding the population of people in different parts of a city and helps town planners regarding allocation of facilities (e.g. waste management facilities). However, in many developing countries the information on people who live in different segments of cities is either lacking or inadequate. This often pose a greater challenge to town planners, thus, facilities provided is either too small or too big for the 
target population. A possible way to minimize the problem is for waste management board officials to keep record of the volume of solid waste materials collected from dump sites in each part of the city. This will give them an idea about areas where waste materials have increased and the necessary action to be taken (e.g. increase in number of dump sites and frequency of collecting waste materials from dump sites) to sustain good environmental quality.

The coefficient associated with awareness of solid waste disposal laws has a positive and statistically significant effect on the respondents' perceptions of solid waste management services. This reveals that respondents who were aware about waste disposal laws were more likely to be satisfied with solid waste management. If a respondent is informed about laws regarding solid waste disposal, the probability of being satisfied with solid waste management increases by 0.099 . People who are informed about laws are often more learned and should know more about rights regarding the environment. It is the right of every Nigerian to have access to a clean environment and the government has a responsibility to provide such environment for the Nigerian residents. People who know their rights have the potential to ask questions and report any abnormalities regarding solid waste management to the appropriate authorities. As in other societies, private individuals do not often like to engage in legal battle with the public sector because of the costs associated with such an action. It does appear that solid waste management services in the study area were more effective in some parts of the city (e.g. areas occupied by more learned people). For solid waste management to be sustainable, all the target area needs to be treated equally because if there is incidence of deterioration of environmental quality in one segment of the area, it is more likely that in the long-run the impacts will be also felt by other segments of that area. For example, if there is a disease out break in some parts of a city, it can spread to other areas if it is not contained. Moreover, there is often more cost to contain a disease out break associated with waste management (e.g. costs associated with cleaning the environment, medicines and lives that may be lost). Thus, it will be more beneficial to the society if all people get access to solid waste management facilities equally. The coefficient associated with sanitary inspectors has a positive and statistically significant impact on respondents' perceptions of solid waste management. This implies that respondents who live in areas where the activities of sanitary inspectors were more felt, were more likely to be satisfied with solid waste management. If a respondent lives in areas where activities of sanitary inspectors are more felt the probability of being satisfied with, solid waste management increases by 0.257 . As in many societies, individuals often appear to be more effective in their activities in the presence of their superiors. It seems that the solid waste management workers were often more effective in areas where sanitary inspectors visit more frequently. This suggests that solid waste management services are more likely to be more effective if there is a better supervision of waste management workers.

The coefficient associated with gender was not statistically significant for perceptions of solid waste management.

\section{CONCLUSION}

Solid waste management strategies in urban areas are often more sustainable when local residents are involved. However, in many developing countries the strategies have been implemented with little or no considerations of local condition. If all stakeholders (government, private sector and local residents) in waste management are involved, it will help to reduce the waste disposal problems and consequently improve environmental quality in less developed countries. Therefore, waste management strategy must be inclusive, fully integrated with economic and social practices, and incorporate all sectors of society, i.e. a wide range of social groups and actors must be actively involved. Thus, the kind of research that is explored in this paper is necessary, but it is limited to only one part of the problem. This study has focused on urban residents' perceptions of solid waste management in one city in one country. It is also necessary to do research in other areas, such as cost-benefit analysis of public versus private provision of solid waste management services and governance in waste management sector. The research findings can contribute to the knowledge about the value that urban residents have for private sector participation in solid waste management. Although, the study have been conducted in a city in southwest Nigeria, the findings reported in this paper can be applied in other developing countries which has similar situation as Nigeria. The 
data used for the study was generated from Ilorin, the capital of Kwara State in southwest Nigeria. The results show that more than $80 \%$ of the respondents were not satisfied with solid waste management. Although, the motivation regarding private sector participation in solid waste management is to improve environmental quality in Ilorin, it is still common to see waste materials littered all areas in and around dump sites. This reveals that the involvement of private sector in partnership with government agency in the provision of solid waste management services has not been very successful.

The effect of different variables on urban residents' perceptions of solid waste management was estimated with a binary logit model. The results from the statistical analysis show that individuals who have more money, spend more time to travel to dump sites, and married ons were less likely to be satisfied regarding solid waste management. Those who were informed about waste disposal regulations and live in area where the services of sanitary inspectors were strongly felt, were more likely to be satisfied. The results from the study suggest that there is a positive relationship between perceptions of solid waste management and awareness of laws regarding waste disposal, as well as sanitary inspectors. This calls for a mass environmental campaign geared towards educating pubic about laws associated with waste management and sanitary inspectors should be more active in monitoring activities of private firms involved in solid waste management. The environmental campaign must be followed by a commitment on the part of the government agency. Efforts should be made to provide more functional waste dumping sites with frequent collections. There is a need to reduce the volume of solid waste generated by Ilorin residents both through changes in societal attitudes and technology. It is also important to develop strategies that encourage recycling of waste materials. The needs of public regarding solid waste management may vary among different housing types and areas. Thus, it is important to consider this variation when designing a solid waste management strategy. A bottom-up and participatory solid waste management is important to improve environmental quality in Ilorin, Nigeria, as well as in other developing countries.

\section{ACKNOWLEDGEMENTS}

The authors of this paper would like to thank all persons who assisted in administering surveys.
Appreciation goes to all Ilorin residents who participated in the survey.

\section{REFERENCES}

Adedibu, A. A., (1985). A comparative analysis of solid waste composition and generation in two cities of a developing nation. The Environ., 5 (2), 123-127 (5 pages).

Asafu-Adejaye, J., (2000). Environmental Economics for nonEconomists. World Scientific Publishing CO. Pte Ltd, Australia.

Asase, M.; Yanful, E. K.; Mensah, M.; Stanford, J.; Amponsah, S., (2009). Comparison of municipal solid waste management systems in Canada and Ghana: a case study of the cities of London, Ontario, and Kumasi, Ghana. Waste Manage., 29 (10), 2779-2786 (8 pages).

Blanchard, O., (2009). Macroeconomics. Pearson Education, Inc., Boston.

Blight, G., (2008). Slope failures in municipal solid waste dumps and landfills: a review. Waste Manage. Res., 26 (5), 448463 (16 pages).

Brunner, P. H.; Fellner, J., (2007). Setting priorities for waste management strategies in developing countries. Waste Manage. Res., 25 (3), 234-240 (7 pages).

Chien, M. K.; Shih, L. H., (2007). An empirical study of the implementation of green supply chain management practices in the electrical and electronic industry and their relation to organizational performances. Int. J. Environ. Sci. Tech., 4 (3), 383-394 (12 Pages).

Cointreau, S., (2006). Occupational and Environmental Health Issues of Solid Waste Management: Special Emphasis on Middle and Lower-Income Countries. World Bank, Washington, DC.

Dangi, M. B.; Cohen, R. R. H.; Urynowicz, M. A.; Poudyal, K. N., (2009). Searching for a way to sustainability: technical and policy analysis of solid waste issues in Kathmandu. Waste Manage. Res., 27 (3), 295-301 (7 pages).

De Oliveria Simonetto, E.; Borenstein, D., (2007). A decision support system for the operational planning of solid waste collection. Waste Manage., 27 (10), 1286-1297 (12 pages).

Ezebilo, E. E., (2010a). Conservation of a leafy vegetable important for communities in the Nigerian rainforest. Forest Ecol. Manage., 259, 1660-1665 (6 pages).

Ezebilo, E. E., (2010b). Community-based Preferences for Economic Incentives to Promote Biodiversity Conservation in a Tropical Rainforest. Int. J. Environ. Res., 4 (3), 501506 (6 pages).

Ezebilo, E. E.; Mattsson, L.; Afolami, C. A., (2010). Economic Value of Ecotourism to Local Communities in the Nigerian Rainforest Zone. J. Sustain. Develop., 3 (1), 51-60 (10 pages).

Greene, W. H., (2003). Econometric Analysis, 5 ${ }^{\text {th }}$ Ed., Prentice Hall, New Jersey.

Gujarati, D. N., (2006). Essentials of Econometrics, $3^{\text {rd }}$ Ed., McGraw-Hill/Irwin, New York.

Hanley, N.; Shogren, J. F.; White, B., (2007). Environmental economics in theory and practice. Palgrave Macmillan, New York.

Harris, J. M., (2006). Environmental Natural Resources Economics: A Contemporary Approach. Houghton Mifflin Company, New York. 
Hassan, R.; Nhemachena, C., (2008). Determinants of African farmers' strategies for adapting to climate change: Multinomial choice analysis. Afr. J. Agr. Res. Econ., 2 (1), 83-104 (12 pages).

Jimoh, H. I., (1997). Individual Rainfall Events and Sediment Generation on Different Surface in Ilorin. Ph.D. Thesis, University of Ilorin, Nigeria.

Kanat, G., (2010). Municipal solid-waste management in Istanbul. Waste Manage., 30 (8-9), 1737-1745 (9 pages).

Kwara State of Nigeria, (1997). Kwara State Diary, Government Press, Ilorin Nigeria.

Kwara State Waste Management Council, (2007). $2^{\text {nd }}$ phase of Green / Clean - Campaign Booklet. Kwara State Government, Nigeria.

Longe, E. O.; Longe, O. O.; Ukpebor, E. F., (2009). People's perception on household solid waste management in Ojo Local Government Area in Nigeria. Iran. J. Environ. Health. Sci. Eng., 6 (3), 209-216 (8 pages).

Madden, D.; Nolan, A.; Nolan, B., (2005). GP reimbursement and visiting behaviour in Ireland. Health Econ., 14 (10) 1047-1060 (14 pages).

Muderrisoglu, H.; Altanlar, A., (2011). Attitudes and behaviour of undergraduate students toward environmental issues. Int. J. Environ. Sci. Tech., 8 (1), 159-168 (10 pages).

National Population Commission, (2006). Final Results, Kwara State.

Neter, J.; Wasserman, W.; Kunter, M. H., (1989). Applied Linear Regression Models.Homewood, IL: Irwin.

Nouri, J.; Fatemi, M. R.; Danekar, A.; Fahimi, F. G.; Karimi, D., (2009). Determination of environmentally sensitive zones along Persian Gulf coastlines through geographic information system. J. Food Agr. Environ., 7 (2), 718-725 (8 pages).

O'Brien, R. M., (2007). A caution regarding rules of thumb for variance inflation factors.Qual. quant., 41 (5), 673-690 (18 pages).

Olorunfemi, J. F., (1982). Application of aerial photography to population estimation in Nigeria.Geojournal, 6 (3), 225230 (6 pages).

Oteng-Ababio, M., (2010). Private sector involvement in solid waste management in the Greater Accra Metropolitan Area in Ghana. Waste Manage. Res., 28 (4), 322-329 (8 pages).

Tehrani, S. M.; Karbassi, A. R.; Ghoddosi, J.; Monavvari, S. M.; Mirbagheri, S. A., (2009). Prediction of energy consumption and urban air pollution reduction in e-shopping. J. Food Agr. Environ., 7 (3-4), 898-903 (5 pages).

Tehrani, S. M.; Karbassi, A. R.; Monavari, S. M.; Mirbagheri, S. A., (2010). Role of E-shopping Management Strategy in Urban Environment. Int. J. Environ. Res., 4 (4), 681-690 (10 pages).

Tietenberg, T.; Lewis, L., (2010). Environmental Economics and Policy. Pearson, Sydney.

UNICEF., (2006). Solid and Liquid Waste Management in Rural areas. A Technical Note, 2006.

UNICEF., (2001). Waste Disposal System, Sanitations and Policies Objective. World Health Report, 2002.

Varian, H. R., (2010). Intermediate Microeconomics: A Modern Approach. W.W. Norton and Company, New York.

Verbeek, M., (2007). A Guide to Modern Econometrics, $2^{\text {nd }}$ edition. John Wiley and sons Ltd, West Sussex, England.

AUTHOR (S) BIOSKETCHES

Ezebilo, E. E., Ph.D., Postdoctoral Fellow, Southern Swedish Forest Research Center, Swedish University of Agricultural Sciences, Sweden. Email: eugene.ezebilo@slu.se

Animasaun, D. E., M.Sc., Department of Public Health, Malmo University, Sweden. E-mail: jmartx3@yahoo.co.uk

How to cite this article: (Harvard style)

Ezebilo, E. E.; Animasaun, D. E., (2011). Households' perceptions of private sector municipal solid waste management services: A binary choice analysis. Int. J. Environ. Sci. Tech., 8 (4), 677-686. 